\title{
Production and Characterization of Monoclonal Antibodies Specific for Mycobacterium bovis
}

\author{
By P. R. WOOD, ${ }^{1 *}$ J. RIPPER, ${ }^{1}$ A. J. RADFORD, ${ }^{1}$ P. G. BUNDESEN,$^{2}$ \\ D. B. RYLATT,$^{2}$ L. E. COTTIS, ${ }^{2}$ M. JOHN ${ }^{2}$ AND P. PLACKETT ${ }^{1}$ \\ ${ }^{1}$ CSIRO Division of Animal Health, Animal Health Research Laboratory, Private Bag No. 1 , \\ Parkville, Vic. 3052, Australia \\ ${ }^{2}$ Agen Biomedical Ltd, Acacia Ridge, Qld. 4110, Australia
}

(Received 1 March 1988; revised 24 May 1988)

\begin{abstract}
A series of monoclonal antibodies (MAbs), specific for Mycobacterium bovis and BCG strains, were tested extensively for cross-reactivity to a wide range of mycobacterial species using ELISA, Western blotting and dot-blot analysis. The MAbs bound specifically to $M$. bovis and BCG and showed limited cross-reactivity with some strains of $M$. tuberculosis. All these MAbs recognized a $22 \mathrm{kDa}$ protein previously termed MPB70, and by competitive ELISA analysis appeared to detect at least three $M$. bovis-specific determinants on the MPB70 molecule.
\end{abstract}

\section{INTRODUCTION}

The development of reliable serological tests for the diagnosis of tuberculosis in humans and cattle has been complicated by the large degree of cross-reactivity between antigens of Mycobacterium tuberculosis, M. bovis and a wide range of other mycobacteria (Krambovitis, 1987; Grange, 1984). The production of monoclonal antibodies (MAbs) specific for these two species has therefore been of interest for the isolation and characterization of species-specific antigens for use in serological assays. Several groups (Engers et al., 1985; Ivanyi et al., 1985) have produced MAbs specific for the $M$. tuberculosis complex of organisms (M. tuberculosis, $M$. bovis, BCG and M. africanum). Only Morris et al. (1985) have reported a MAb that recognizes an epitope present on $M$. bovis which is not present on BCG, $M$. tuberculosis or a large range of other mycobacterial species.

We have produced MAbs specific for determinants of $M$. bovis. These have been used to characterize specific antigens for incorporation into serological and cellular assays for the diagnosis of bovine tuberculosis.

\section{METHODS}

Mycobacterial antigens for Western blotting. The strains of mycobacteria used were obtained from the following sources in Australia: MAIS ( $M$. avium-intracellulare-scrofulaceum) complex, M. kansasii, M. terrae, M. gordonae and $M$. fortuitum from the Department of Health, Brisbane; $M$. phlei and $M$. paratuberculosis from the Veterinary Research Institute, Parkville; $M$. bovis strain AN5, BCG, and $M$. tuberculosis strains PN, C and DT from the Commonwealth Serum Laboratories, Parkville; M. tuberculosis strain H37Rv from the Fairfield Hospital, Fairfield; and Norcardia asteroides from the School of Veterinary Science, University of Melbourne. The two remaining strains (PMC203, PMC235) were from our own collection. M. leprae antigens were supplied by $\mathrm{Dr}$ R. Garcia, University of Sydney. Mycobacteria were grown on modified Middlebrook 7H11 medium (Gallagher \& Horwill, 1977) in Petri dishes at $37^{\circ} \mathrm{C}$ in an atmosphere of $9 \% \mathrm{CO}_{2}$-in-air for 7 weeks. Then $2 \mathrm{ml}$ normal saline $(0.15 \mathrm{M}-\mathrm{NaCl})$ was added to the surface of each of two plates and bacteria gently scraped off using an angled

Abbreviations: ABTS, 2,2'-azino-di-(3-ethylbenzthiazoline sulphonic acid), HRP, horseradish peroxidase; MAb, monoclonal antibody; MAIS, Mycobacterium avium-intracellulare-scrofulaceum. 
pipette. The bacterial suspensions were adjusted to approximately the same turbidity $\left(10^{9} \mathrm{bacterial} \mathrm{ml}^{-1}\right)$ and heat-killed in a $70^{\circ} \mathrm{C}$ waterbath for $2 \mathrm{~h}$. They were then centrifuged at $4000 \mathrm{~g}$ for $15 \mathrm{~min}$ and the pellets resuspended in 10 times their volume of saline. Sodium dodecyl sulphate (SDS) was added to each suspension to give a final concentration of $4 \%(w / v)$ SDS. Samples were then boiled at $100^{\circ} \mathrm{C}$ for 10 min to produce SDSextracted antigens.

Culture-filtrate antigen and sonicated antigen. Mycobacteria were grown in Dubos broth medium (DIFCO) as static cultures at $37^{\circ} \mathrm{C}$ for 10 weeks in an atmosphere of $9 \% \mathrm{CO}_{2}$-in-air. One hundred ml of medium was inoculated with $1 \mathrm{ml}$ of a suspension of bacteria in normal saline. The opacity of these suspensions was equal to or denser than Brown's opacity tube 8. Cultures were then centrifuged at $4000 \mathrm{~g}$ for $15 \mathrm{~min}$, after which the supernate was removed and filtered sequentially through $0.45 \mu \mathrm{m}$ and $0.22 \mu \mathrm{m}$ cellulose acetate filters, for the preparation of culture-filtrate antigen. Filtered supernates were concentrated 10-fold with Aquacide II (Calbiochem) and dialysed against distilled water overnight. The total protein content was estimated by measuring UV absorbance at $280 \mathrm{~nm}$. For preparation of sonicated antigen the cell pellet $(0 \cdot 2-0.5 \mathrm{~g})$ was washed in saline, resuspended in 10 times its volume of saline and heat-killed at $70^{\circ} \mathrm{C}$ for $2 \mathrm{~h}$. The cells were then sonicated for $3 \mathrm{~min}$ (Vibra, cell sonicator, $8 \times 30 \mathrm{~s}$ bursts of $15 \mathrm{~W}$ ) and the suspension centrifuged at $13000 \mathrm{~g}$ for $10 \mathrm{~min}$ to pellet cellular debris. The supernate prepared in this manner is referred to as sonicated antigen.

Preparation of anti-M. bovis MAbs. Balb/c mice (6-8 weeks old) were injected subcutaneously on three occasions at 2 week intervals with $0 \cdot 1 \mathrm{ml}$ of a suspension of aluminium hydroxide (Herbert, 1978) in phosphate-buffered saline $(0 \cdot 1 \mathrm{M}$-sodium phosphate, $0 \cdot 15 \mathrm{M}-\mathrm{NaCl}$; PBS) $\mathrm{pH} 7.2$ containing a sonicate of UV-killed $M$. bovis $(10 \mu \mathrm{g}$ protein $\left.\mathrm{ml}^{-1}\right)$. For production of UV-killed material, $5 \mathrm{ml}$ bacterial suspension $\left(2 \mathrm{mg} \mathrm{ml}^{-1}\right.$, wet weight) was placed in a $90 \mathrm{~mm}$ Petri dish $16 \mathrm{~cm}$ from a UV source $(15 \mathrm{~W})$ and exposed for $60 \mathrm{~min}$. Samples of the bacterial suspension were then plated to check for sterility, and the remainder was concentrated to $10 \mathrm{mg} \mathrm{ml}^{-1}$ and sonicated as described above.

Five days after the last injection the spleens of the mice were removed for fusion with NS-1 myeloma cells. Hybridoma production, the MAb screening assay, isotyping and production of ascites fluid were done by the methods described by Bundesen et al. (1985), with $M$. bovis sonicate as the screening antigen. Selected hybridomas, chosen on the basis of the screening assay, were subcloned by limiting dilution and a number of monoclonal anti$M$. bovis antibody-secreting cell lines were selected for expansion into mass culture and production of ascitic fluids. All assays of the MAbs were done using ascites fluid preparations.

ELISA. The ELISA method used was adapted from that described by Grange et al. (1980). Polystyrene microtitre trays (Disposable Products) were coated with $0.5 \mu \mathrm{g}$ per well of $M$. bovis culture filtrate or mycobacterial sonicate antigen in PBS (pH 7.2) overnight at $4{ }^{\circ} \mathrm{C}$. Trays were then washed four times in PBS with $0.05 \%$ Tween 20 (PBST), blocked with $2.5 \%$ (w/v) non-fat powdered milk in PBS (Blotto) and incubated with MAbs diluted to their optimum concentration in PBST. Trays were incubated for $90 \mathrm{~min}$ at room temperature, washed and reincubated with an anti-mouse IgG labelled with horseradish peroxidase (HRP; Sigma). After 90 min the trays were washed and incubated with ABTS substrate [2,2'-azino-di-(3-ethylbenzthiazoline sulphonic acid)] for $30 \mathrm{~min}$. Results were read at $405 \mathrm{~nm}$ in a Titertek Multiskan.

Competitive ELISA. The MAbs were labelled with HRP as previously described (Rylatt et al., 1985). All HRPconjugated MAbs were titrated on $M$. bovis AN5 culture-filtrate antigen, and used in subsequent ELISAs at their optimal concentration. After coating with $M$. bovis antigen $(0.5 \mu \mathrm{g}$ per well in $50 \mu \mathrm{l})$, trays were blocked with $2.5 \%$ Blotto for $90 \mathrm{~min}$. Serial dilutions of unlabelled MAbs were then added in duplicate and incubated for $90 \mathrm{~min}$ at room temperature followed by $50 \mu \mathrm{l}$ of a HRP-labelled MAb. After a further $2 \mathrm{~h}$ incubation the trays were washed and incubated for $30 \mathrm{~min}$ with substrate (ABTS). Results were calculated as a percentage of the $A_{405}$ obtained with the HRP-labelled MAb bound at its optimum concentration.

Dot-blotting. Sonicated antigen preparations were diluted to $10 \mu \mathrm{g} \mathrm{ml}^{-1}$ and $100 \mu \mathrm{l} \mathrm{samples} \mathrm{applied} \mathrm{to} \mathrm{each} \mathrm{well}$ of a dot-blotting manifold loaded with nitrocellulose (Bio-Rad, $0.45 \mu \mathrm{m}$ pore size). Samples were left to bind overnight at $4{ }^{\circ} \mathrm{C}$, after which the filters were rinsed once in PBS and then blocked for 90 min at room temperature with Blotto. After being washed four times in PBST the filters were probed for $90 \mathrm{~min}$ at room temperature with $\mathrm{MAb}$ diluted in PBST to its optimum concentration as ascertained by probing $M$. bovis antigen bound to nitrocellulose (Hawkes et al., 1982). Following a further four washes in PBST, filters were incubated with antimouse HRP conjugate, washed again, and developed in 4-chloro-1-naphthol substrate $\left(0.4 \mathrm{mg} \mathrm{ml}^{-1}\right.$ in $100 \mathrm{mM}-$ Tris $/ \mathrm{HCl} \mathrm{pH} 7 \cdot 4$, containing $0.03 \% \mathrm{H}_{2} \mathrm{O}_{2}$ ).

$S D S-P A G E$ and Western blotting. Samples of mycobacteria grown on $7 \mathrm{H} 11$ medium were solubilized in Tris/HCl buffer $\mathrm{pH} 6.8$ containing $2 \%(\mathrm{w} / \mathrm{v})$ SDS, $5 \%(\mathrm{v} / \mathrm{v})$ glycerol and $0.002 \%(\mathrm{w} / \mathrm{v})$ bromophenol blue by heating at $100^{\circ} \mathrm{C}$ for $5 \mathrm{~min}$. Vertical slab SDS-PAGE was done as described by Laemmli (1970). Proteins were transferred overnight by electroblotting to nitrocellulose (Towbin et al., 1979), blocked with Blotto for $60 \mathrm{~min}$, then probed for $2 \mathrm{~h}$ with MAbs diluted in PBST to an appropriate concentration as previously determined in the dot-blot system. The blots were incubated with HRP-conjugated affinity-purified rabbit anti-mouse IgG, followed by the HRP substrate (4-chloro-1-naphthol) until the colour product became visible. 
Table 1. MAbs specific for M. bovis

$\begin{array}{lll}\text { Original no. } & \text { Code } & \text { Isotype } \\ 1 \mathrm{~A} 3 / 157 & \text { SB1 } & \text { IgG1 } \\ 4 \mathrm{C} 6 / 70 & \text { SB2 } & \text { IgG1 } \\ 2 \mathrm{D} 6 / 8 & \text { SB3 } & \text { IgG1 } \\ 2 \mathrm{D} 6 / 150 & \text { SB4 } & \text { IgG2a } \\ 2 B 5 / 39 & \text { SB5 } & \text { IgM } \\ 2 \mathrm{C} 5 / 18 & \text { SB6 } & \text { IgG1 } \\ 4 \mathrm{~B} 5 / 121 & \text { SB7 } & \text { IgG2a } \\ 2 \mathrm{C} 3 / 126 & \text { SB8 } & \text { IgG1 } \\ 3 \mathrm{D} 3 / 14 & \text { SB9 } & \text { IgA } \\ 4 C 3 / 17 & \text { SB10 } & \text { IgG2a }\end{array}$

Table 2. Specificity of MAbs SB1 to SB10 for antigens from various mycobacterial species

The MAbs were tested on antigens from the organisms listed, by ELISA, dot-blot and Western blot analysis. The antigen preparations used were : ELISA, culture filtrate or sonicated; dot-blot, sonicated; and Western blot, SDS-extracted. All results were repeated on at least two or three occasions.

Source of antigens

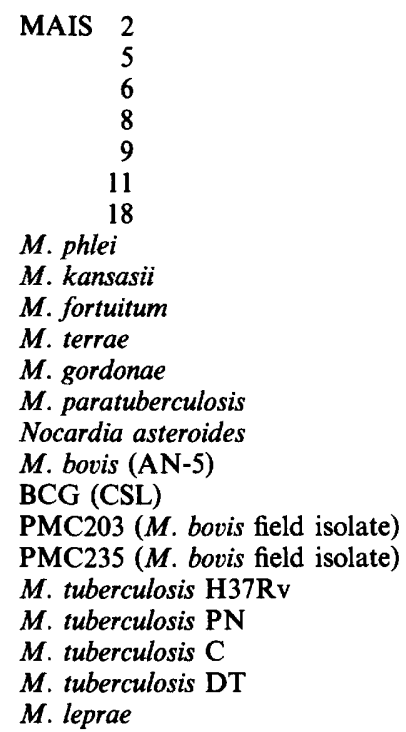

ELISA Dot-blot Western blot

$\begin{array}{ccc}- & - & - \\ - & - & - \\ - & - & - \\ \text { ND } & - & - \\ - & - & - \\ \text { ND } & - & - \\ - & - & - \\ - & - & - \\ - & - & - \\ - & - & - \\ - & - & - \\ - & - & - \\ - & - & + \\ \text { ND } & - & + \\ + & + & + \\ + & + & + \\ + & + & - \\ + & + & - \\ - & \pm & - \\ - & - & - \\ - & - & \\ - & - & - \\ \text { ND } & - & \end{array}$

ND, not done.

\section{RESULTS AND DISCUSSION}

Hybridomas secreting antibody to $M$. bovis were tested for reactivity to a limited range of MAIS complex organisms. Following the initial screening in an ELISA assay and cloning, 10 MAbs reacting only with $M$. bovis antigen were selected for detailed analysis.

The code and isotype of these MAbs are listed in Table 1 (the original designations are included as the MAbs have been distributed to several laboratories under these codes). The specificity of the selected MAbs for a wide range of mycobacterial species was examined in three different assays (ELISA, dot-blot analysis and Western blotting) using culture-filtrate, sonicated or SDS-extracted antigen preparations. All 10 of these MAbs appeared to be specific for wildtype $M$. bovis strains and $M$. bovis BCG (Table 2). Cross-reactivity was seen with one isolate of M. tuberculosis in the dot-blot system. Results of the dot-blots given in Table 2 are for sonicated antigen, but culture-filtrate preparations of the mycobacteria were also probed on dot-blots with 
(a)

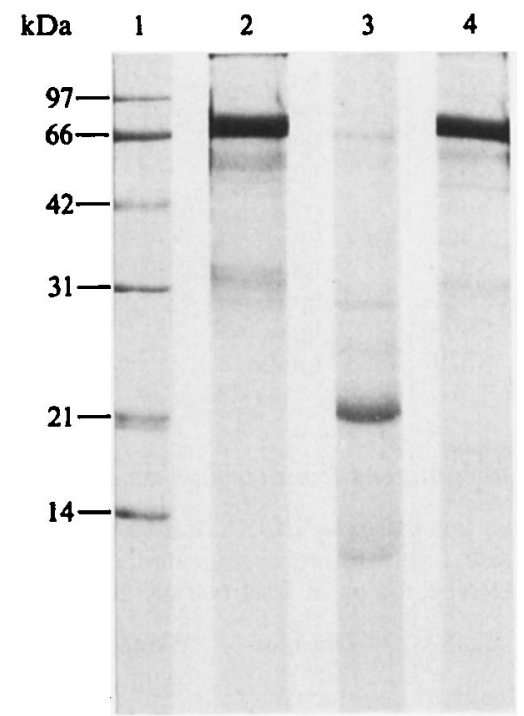

(b)

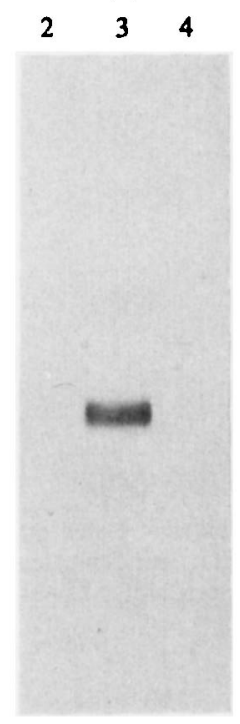

Fig. 1. (a) SDS-PAGE stained with Coomassie Brilliant Blue, and (b) Western transfer probed with MAb SB10, of sonicated antigen preparations. Lane 1, Bio-Rad low-MW markers; lane 2, M. phlei; lane 3, M. bovis; lane 4, M. tuberculosis H37Rv.

\section{Table 3. Competitive analysis of $M A$ Abs recognizing $M$. bovis culture-filtrate antigen}

The inhibition of binding of HRP-labelled MAb by unlabelled MAb was scored as positive for $>50 \%$ inhibition, plus/minus for $30-50 \%$ inhibition and negative for $<30 \%$ inhibition. All results were repeated on at least two or three occasions.

\begin{tabular}{|c|c|c|c|c|c|c|c|c|c|c|}
\hline \multirow{2}{*}{$\begin{array}{l}\text { Unlabelled } \\
\text { MAb }\end{array}$} & \multicolumn{10}{|c|}{ HRP-labelled MAb: } \\
\hline & SB1 & SB2 & SB3 & SB4 & SB5 & SB6 & SB7 & SB8 & SB9 & SB 10 \\
\hline SB1 & + & + & + & - & - & - & - & - & - & - \\
\hline SB2 & + & + & + & + & - & - & - & - & - & - \\
\hline SB3 & + & + & + & + & - & - & - & - & - & - \\
\hline SB4 & - & + & + & + & - & - & - & - & - & - \\
\hline SB5 & - & - & - & - & + & + & + & - & - & - \\
\hline SB6 & - & - & - & - & + & + & + & + & - & \pm \\
\hline SB7 & - & - & - & - & \pm & + & + & \pm & - & $=$ \\
\hline SB8 & - & - & - & - & - & \pm & + & $\bar{t}$ & - & - \\
\hline SB9 & - & - & - & - & - & - & - & - & + & + \\
\hline SB10 & - & - & - & - & - & \pm & - & - & + & + \\
\hline
\end{tabular}

the SB MAbs. $M$. bovis culture filtrates contained large amounts of the recognized antigen, but the other mycobacteria produced no antigen in the culture filtrate detectable with the MAbs. However, not all the mycobacteria tested grew well on the Dubos medium required for production of culture filtrate, and consequently sonicate or SDS-extracted antigen was also used to examine the SB series of MAbs for cross-reactivity.

In the Western blot analysis of SDS-extracted or sonicated $M$. bovis antigen all the SB MAbs bound to a $22 \mathrm{kDa}$ protein (Fig. 1). However, when Western blots were performed with some sonicate or Ribi press lysate antigen preparations from $M$. bovis, multiple bands of higher molecular mass were often detected with these MAbs (T. Fifis, personal communication).

Competitive ELISA analysis between enzyme-labelled and unlabelled antibodies on culturefiltrate antigen of $M$. bovis suggested that these MAbs recognize at least three distinct antigenic determinants on a $22 \mathrm{kDa}$ protein produced by $M$. bovis (Table 3). The individual MAbs within the three groupings may not necessarily recognize exactly the same epitope, as individual MAbs within a group were not equally efficient in blocking binding of other MAbs within that group. 
A large range of MAbs specific for the $M$. tuberculosis complex of organisms have now been described (Engers et al., 1985), and used widely to isolate and characterize $M$. tuberculosiscomplex-specific antigens (Young, 1985). These MAbs recognize three major proteins $(14,38$ and $65 \mathrm{kDa}$ ) which are distinct from the protein detected by the SB series of MAbs described in this paper, and none of them discriminate between $M$. tuberculosis and $M$. bovis strains.

The $22 \mathrm{kDa}$ protein recognized by the SB MAbs is most likely that described by Nagai et al. (1981), and termed MPB70. Both proteins have similar molecular masses, are present in high concentration in culture filtrate (in some strains more than $10 \%$ of the total protein secreted), often occur in higher molecular mass forms, and appear to be limited to the $M$. tuberculosis complex of organisms. The binding of MAbs to multiple bands in mycobacterial extracts, as seen with the SB MAbs (T. Fifis, personal communication), has also been reported by others (Young et al., 1987).

Harboe et al. (1986) detected some cross-reactivity between MPB70 and Nocardia asteroides; however, the SB series of MAbs recognize epitopes on MPB70 that are not present in $N$. asteroides. The finding that MPB70 is detectable in M. tuberculosis and some BCG strains at only very low concentrations (Harboe \& Nagai, 1984) would explain the low level of crossreactivity of the SB MAb to $M$. tuberculosis strains. This would also explain why none of the many MAbs produced to the $M$. tuberculosis complex of organisms appear to recognize MPB70, as the strains used for immunization were all low-level producers of this protein (Minden et al., 1984; Kolk et al., 1984).

The MAbs reported in this paper recognize antigenic determinants that are specific for $M$. bovis and BCG. Competitive binding and Western blot studies of these MAbs with various $M$. bovis culture-filtrate antigen preparations suggest that they detect at least three different epitopes on a $22 \mathrm{kDa}$ protein. These MAbs are also distinct from the $M$. bovis-specific MAbs (MB-5) described by Morris et al. (1985), which identified a $30 \mathrm{kDa}$ protein that is not present in BCG or culture-filtrate preparations from $M$. bovis. We have recently reported the isolation and sequencing of the MPB70 gene from a $\lambda \mathrm{gt} 11$ expression library of $M$. bovis (Radford et al., 1988). The characterization of the species-specific epitopes on this protein will hopefully provide antigens for use in highly specific diagnostic tests for bovine tuberculosis.

The authors gratefully acknowledge the assistance of L. A. Corner. This work was supported by grants from the Australian Meat and Livestock Research and Development Corporation and the National Brucellosis and Tuberculosis Eradication Campaign. The antigen used for immunization of mice was kindly provided by the Animal Research Institute, Yeerongpilly.

\section{REFERENCES}

Bundesen, P. G., Wyatt, D. M., Cottis, L. E., Blake, A. S., Massingham, D. A., Fletcher, W. A., Street, G., Welch, J. S. \& Rylatt, D. B. (1985). Monoclonal antibodies directed against Brucella abortus cell surface antigens. Veterinary Immunology and Immunopathology 8, 245-260.

ENGERS, H. D., BLOOM, B. R. \& Godal, T. (1985). Monoclonal antibodies against mycobacterial antigens. Immunology Today 6, 345, 347-348.

Gallagher, J. \& Horwill, D. M. (1977). A selective oleic acid albumin agar medium for the cultivation of Mycobacterium bovis. Journal of Hygiene 79, 155160.

Grange, J. M. (1984). The humoral immune response in tuberculosis: its nature, biological role and diagnostic usefulness. Advances in Tuberculosis Research 21, 1-78.

Grange, J. M., Gibson, J. \& Nassau, E. (1980). Enzyme-linked immunosorbent assay (ELISA): a study of antibodies to Mycobacterium tuberculosis in the IgG, IgA and IgM classes in tuberculosis, sarcoidosis and Crohn's disease. Tubercle 61, 145152.

Harboe, M. \& NaGai, S. (1984). MPB70, a unique antigen of Mycobacterium bovis BCG. American Review of Respiratory Disease 129, 444-452.

harboe, M., Nagai, S., Patarroyo, M. E., Torres, M. L., RamireX, C. \& CRUZ, N. (1986). Properties of proteins MPB64, MPB70, and MPB80 of Mycobacterium bovis BCG. Infection and Immunity 52, 293302.

HaWkes, R., Niday, E. \& GoRdon, J. (1982). A dot immunobinding assay for monoclonal and other antibodies. Analytical Biochemistry 119, 142-147.

Herbert, W. J. (1978). Mineral-oil adjuvants and the immunization of laboratory animals. In Handbook of Experimental Immunology, 3rd edn, vol. 3, pp. A3.1A3.15. Edited by D. M. Weir. Oxford: Blackwell Scientific.

IVANYI, J., Morris, J. A. \& Keen, M. (1985). Studies with monoclonal antibodies to mycobacteria. In Monoclonal Antibodies Against Bacteria, vol. 1, pp. 
59-90. Edited by A. J. L. Macario \& E. Conway de Macario. Orlando: Academic Press.

KolK, A. H. J., Ho, M. L., KlAtser, P. R., EgGelte, T. A., KuiJPER, S., DE JONGE, S. \& VAN LEEUWEN, J. (1984). Production and characterization of monoclonal antibodies to Mycobacterium tuberculosis, $M$. bovis (BCG) and M. leprae. Clinical and Experimental Immunology 58, 511-521.

KRAMBOVITIS, E. (1987). Serodiagnosis of tuberculosis in perspective. Serodiagnosis and Immunotherapy 1, 7-19.

LAEMMLI, U. K. (1970). Cleavage of structural proteins during the assembly of the head of bacteriophage T4. Nature, London 227, 680-685.

Minden, P., Kelleher, P. J., Freed, J. H., Nielsen, L. D., BRenNaN, P. J., MCPheron, L. \& MCClatCHY, J. K. (1984). Immunological evaluation of a component isolated from Mycobacterium bovis BCG with a monoclonal antibody to $M$. bovis BCG. Infection and Immunity 46, 519-525.

Morris, J. A., ThORNS, C. J. \& WoOleY, J. (1985). The identification of antigenic determinants on Mycobacterium bovis using monoclonal antibodies. Journal of General Microbiology 131, 1825-1831.

Nagai, S., Matsumoto, J. \& Nagasuga, T. (1981). Specific skin-reactive protein from culture filtrate of
Mycobacterium bovis BCG. Infection and Immunity 31, 1152-1160.

Radford, A. J., Duffield, B. J. \& Plackett, P. (1988). Cloning of a species specific antigen of Mycobacterium bovis. Infection and Immunity 56, 921925.

Rylatt, D. B., Wyatt, D. M. \& Bundesen, P. G. (1985). A competitive enzyme immunoassay for the detection of bovine antibodies to Brucella abortus using monoclonal antibodies. Veterinary Immunology and Immunopathology 8, 261-271.

Towbin, H., Staehelin, T. \& Gordon, J. (1979). Electrophoretic transfer of proteins from polyacrylamide gels to nitrocellulose sheets: procedure and some applications. Proceedings of the National Academy of Sciences of the United States of America 76, 4350-4354.

Young, D. B. (1985). Cloning and expression of mycobacterial genes in E. coli. Immunology Today 6, 296-297.

YounG, D. B., KeNT, L. \& YounG, R. A. (1987). Screening of a recombinant mycobacterial DNA library with polyclonal antiserum and molecular weight analysis of expressed antigens. Infection and Immunity 55, 1421-1425. 